\title{
Chorioretinal Vascular Oxygen Tension in Spontaneously Breathing Anesthetized Rats
}

\author{
A. Shakoor M. Gupta N.P. Blair M. Shahidi \\ Department of Ophthalmology and Visual Sciences, University of Illinois at Chicago, Chicago, III., USA
}

\section{Key Words}

Choroid $\cdot$ Oxygen $\cdot$ Retina

\begin{abstract}
Purpose: To establish baseline and variability of oxygen tension $\left(\mathrm{PO}_{2}\right)$ measurements in the choroid, retinal arteries, capillaries, and veins of spontaneously breathing anesthetized rats and determine the effect of a moderate surgical procedure on the chorioretinal $\mathrm{PO}_{2}$. Methods: Our previously established optical section phosphorescence imaging technique was utilized to measure $\mathrm{PO}_{2}$ in the chorioretinal vasculatures. Imaging was performed in 29 spontaneously breathing rats under ketamine/xylazine anesthesia. In 7 rats, blood was drawn using a surgically implanted femoral arterial catheter and analyzed to determine the systemic arterial $\mathrm{PO}_{2}$. The $\mathrm{PO}_{2}$ measurements in 22 rats without surgery (group 1) and 7 surgically instrumented rats (group 2) were statistically compared. The intrasubject variability was calculated by the average standard deviation (SD) of repeated measurements. Results: The average systemic arterial $\mathrm{PO}_{2}$ was $52 \pm 7 \mathrm{~mm} \mathrm{Hg}$ (mean $\pm \mathrm{SD}$ ) in group 2 . In group 1, the average $\mathrm{PO}_{2}$ measurements in the choroid, retinal arteries, capillaries, and veins were $50 \pm 11,40 \pm 5,39 \pm 6$, and $30 \pm 5 \mathrm{~mm} \mathrm{Hg}$, respectively. No statistically significant $\mathrm{PO}_{2}$ differences in any of the chorioretinal vasculatures were found between the two groups $(p>0.4)$. The intrasubject variability was $3 \mathrm{~mm} \mathrm{Hg}$ in the choroid, retinal arteries, capillaries, and veins. Conclusions: Chorioretinal $\mathrm{PO}_{2}$ measure-
\end{abstract}

ments in spontaneously breathing anesthetized rats have a relatively low variability, indicating that $\mathrm{PO}_{2}$ changes due to various physiological alterations can be reliably assessed.

Copyright $\odot 2007$ S. Karger AG, Basel

\section{Introduction}

Oxygen plays a pivotal role in the maintenance of normal retinal function. Deranged retinal oxygenation is implicated in the development of many retinal diseases including diabetic retinopathy, glaucoma and age-related macular degeneration [1-4]. Rat models of diabetes, glaucoma, and retinal degeneration [5-11] have become available and can be utilized to investigate the role of oxygen in the development of disease-related retinal pathologies.

Several techniques have been utilized to study retinal oxygenation in animals. Retinal tissue hypoxia has been shown to be present in experimental diabetes by inserting oxygen-sensitive microelectrodes through the eye into the retina [12-14]. This technique has also been utilized to measure retinal tissue oxygen consumption in normal animals [15-17], diabetic cats [12], and in a rat model of retinal degeneration [18]. However, placement of microelectrodes has the potential to disturb the retinal microenvironment. Also, oxygenation in only a few retinal locations can be studied, and repeated $\mathrm{PO}_{2}$ measurements at the same location may affect the retinal microenviron-

\section{KARGER}

Fax +4161306 1234 E-Mail karger@karger.ch www.karger.com

\section{(C) 2007 S. Karger AG, Basel}

0030-3747/07/0392-0103\$23.50/0

Accessible online at:

www.karger.com/ore
Mahnaz Shahidi, PhD

Department of Ophthalmology and Visual Sciences

University of Illinois at Chicago, 1855 West Taylor Street

Chicago IL 60612 (USA)

Tel. +1 312413 7364, Fax +1 312413 7366, E-Mail mahnshah@uic.edu 
ment. Subnormal retinal oxygenation response to hyperoxic challenge has been demonstrated in diabetes by magnetic imaging $[19,20]$. However, this technique does not provide a direct measure of tissue $\mathrm{PO}_{2}$ and is limited by its lower resolution compared with optical techniques. Intravascular oxygen tension $\left(\mathrm{PO}_{2}\right)$ has been measured in normal mice and rats by a phosphorescence imaging technique [21-24]. However, due to the limited depth discrimination, the retinal vascular $\mathrm{PO}_{2}$ measurements were likely to have been influenced by the underlying choroid.

We have previously developed a method to measure $\mathrm{PO}_{2}$ separately in the chorioretinal vasculatures noninvasively with respect to the eye [25-27]. The purpose of the current study was to establish the variability and baseline measurements of intravascular chorioretinal $\mathrm{PO}_{2}$ in spontaneously breathing, anesthetized rats. Establishment of these parameters is needed to assess the capability of the system for monitoring $\mathrm{PO}_{2}$ changes over time and detecting $\mathrm{PO}_{2}$ abnormalities due to disease. Additionally, the effect of a moderate surgical procedure on the chorioretinal $\mathrm{PO}_{2}$ was determined.

\section{Materials and Methods}

\section{Animals}

Twenty-nine male Long Evans pigmented rats (450-650 g) were used for the study. The animals were treated in compliance with the Statement for the Use of Animals in Ophthalmic and Vision Research of the Association for Research in Vision and Ophthalmology. The rats were anesthetized using ketamine $(85 \mathrm{mg} /$ $\mathrm{kg}$ i.p.) and xylazine $(3.5 \mathrm{mg} / \mathrm{kg}$ i.p.). Anesthesia was maintained by an intraperitoneal infusion of ketamine and xylazine at the rate of 0.5 and $0.02 \mathrm{mg} / \mathrm{kg} / \mathrm{min}$, respectively. No surgical procedures were performed in 22 rats (group 1). Blood gas analysis was performed in 7 surgically instrumented rats (group 2). The left femoral artery was cannulated and the heparinized catheter was attached to a stopcock. During imaging, blood was drawn from the catheter into a heparinized $0.5-\mathrm{ml}$ syringe that was immediately subjected to blood gas analysis.

The pupils were dilated with $2.5 \%$ phenylephrine and $1 \%$ tropicamide. Rectal temperature was maintained between 37 and $38^{\circ} \mathrm{C}$ via a copper tubing water heater. An oxygen-sensitive molecular probe, either Pd-porphyrin (Frontier Scientific, Logan, Utah, USA) or Oxyphor R2 (Oxygen Enterprises, Philadelphia, $\mathrm{Pa}$., USA), was prepared and injected intravenously [27]. Initially, Pd-porphyrin was used in 22 animals and later Oxyphor R2, which is a formulation of the Pd-porphyrin that is simpler to prepare, was used in 7 animals. Pd-porphyrin oxygen probe was selected due to its sensitivity to oxygen over the range of $\mathrm{PO}_{2}$ typically found in vivo, its peak excitation wavelength that is within the transmission spectrum of the ocular media, and its phosphorescence emission that is minimally absorbed by retinal tissue. Prior to imaging, $1 \%$ hydroxypropyl methylcellulose was applied to the cornea and a glass coverslip was placed on the cornea in order to eliminate its refractive power and to prevent corneal dehydration. The rat was placed in front of the imaging instrument. The laser power was adjusted to $100 \mu \mathrm{W}$, which is safe for viewing according to the American National Standard Institute for Safety Standards [28].

\section{Imaging}

The instrument used for measurements of $\mathrm{PO}_{2}$ separately in the retinal and choroidal vasculatures has been described previously [27]. A laser beam $(\lambda=532 \mathrm{~nm})$ was projected at an oblique angle on the retina following intravenous injection of the probe, and phosphorescence emission was imaged. On the phosphorescence optical section image, choroidal and retinal vasculatures appeared laterally displaced according to their depth location, because the incident laser beam was not coaxial with the viewing axis. Imaging was performed at locations within one-disk diameter from the edge of the optic nerve head.

A frequency-domain approach was used for the measurement of phosphorescence lifetime of the oxygen-sensitive molecular probe. The incident laser light that was used for excitation of the molecular probe and the sensitivity of the camera that was used for detection of the phosphorescence emission were independently modulated. In each eye, phase-delayed images were acquired by varying the phase relationship between the two modulators. The images were analyzed to derive phosphorescence lifetime in the retinal vein, artery, capillaries, and in the choroid [27]. The phosphorescence lifetime measurements were converted to provide measurements of $\mathrm{PO}_{2}$, according to the Stern-Volmer expression: $\tau_{0} / \tau=1+\left(\kappa_{\mathrm{Q}}\right)\left(\tau_{0}\right)\left(\mathrm{PO}_{2}\right)$, where $\mathrm{PO}_{2}(\mathrm{~mm} \mathrm{Hg})$ is the oxygen tension, $\tau(\mu \mathrm{s})$ is the phosphorescence lifetime, $\kappa_{\mathrm{Q}}(1 / \mathrm{mm} \mathrm{Hg} \mu \mathrm{s})$ is the quenching constant for the triplet-state phosphorescence probe, and $\tau_{0}$ is the lifetime in zero oxygen environment. The intrasubject variability was calculated by the average standard deviation (SD) of repeated measurements. Unpaired Student's t test was performed to compare the $\mathrm{PO}_{2}$ measurements between groups. Significance was accepted at $\mathrm{p}<0.05$.

\section{Results}

The systemic arterial and chorioretinal $\mathrm{PO}_{2}$ measurements in group 2 rats are shown in table 1 . The average systemic arterial $\mathrm{PO}_{2}$ was $52 \pm 7 \mathrm{~mm} \mathrm{Hg}$ (mean $+\mathrm{SD}$; $\mathrm{n}=7$ ). The average $\mathrm{PO}_{2}$ in the choroid, retinal arteries, capillaries, and veins were $52 \pm 7,43 \pm 6,38 \pm 6$, and $30 \pm 5 \mathrm{~mm} \mathrm{Hg}$, respectively. $\mathrm{PO}_{2}$ measurements in each of the four vasculatures were divided by the systemic arterial $\mathrm{PO}_{2}$ to derive relative values. Relative to the systemic arterial $\mathrm{PO}_{2}$, the $\mathrm{PO}_{2}$ measurements in the choroid, retinal arteries, capillaries, and veins were $1.0 \pm 0.1,0.8$ $\pm 0.1,0.7 \pm 0.1$, and $0.6 \pm 0.1$, respectively. No statistically significant $\mathrm{PO}_{2}$ difference in the chorioretinal vasculatures was found between the two groups ( $p>0.3$ ). The mean chorioretinal $\mathrm{PO}_{2}$ measurements in group 1, group 2 and combined groups 1 and 2 are shown in ta- 


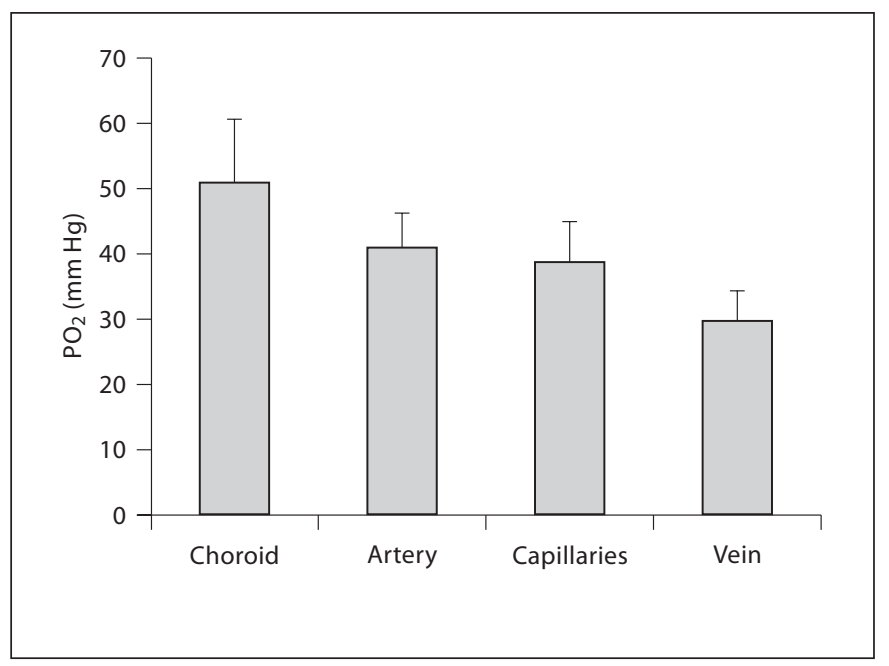

Fig. 1. Chorioretinal $\mathrm{PO}_{2}$ measurements obtained in 29 spontaneously breathing rats under anesthesia. The error bars represent the standard error of the mean.

Table 1. $\mathrm{PO}_{2}$ (means $\pm \mathrm{SD}$ ) measurements in the systemic artery and chorioretinal vasculatures in spontaneously breathing anesthetized surgically instrumented rats (group 2)

\begin{tabular}{|c|c|c|c|c|c|}
\hline \multirow[t]{2}{*}{ Group 2} & \multicolumn{5}{|c|}{$\mathrm{PO}_{2}, \mathrm{~mm} \mathrm{Hg}$} \\
\hline & $\begin{array}{l}\text { systemic } \\
\text { artery }\end{array}$ & choroid & artery & capillaries & vein \\
\hline Rat 1 & 61 & $61 \pm 2$ & $51 \pm 4$ & $48 \pm 5$ & $38 \pm 3$ \\
\hline Rat 2 & 46 & $48 \pm 3$ & $41 \pm 3$ & $38 \pm 5$ & $30 \pm 1$ \\
\hline Rat 3 & 58 & $60 \pm 3$ & $52 \pm 5$ & $41 \pm 4$ & $27 \pm 3$ \\
\hline Rat 4 & 52 & $49 \pm 4$ & $38 \pm 3$ & $38 \pm 2$ & $31 \pm 2$ \\
\hline Rat 5 & 44 & $44 \pm 2$ & $42 \pm 2$ & $38 \pm 2$ & $25 \pm 5$ \\
\hline Rat 6 & 46 & $47 \pm 3$ & $35 \pm 3$ & $28 \pm 2$ & $24 \pm 3$ \\
\hline Rat 7 & 60 & $56 \pm 7$ & $39 \pm 5$ & $33 \pm 5$ & $32 \pm 3$ \\
\hline
\end{tabular}

ble 2. The average combined $\mathrm{PO}_{2}$ measurements in the choroid, retinal arteries, capillaries, and veins were $51 \pm$ $10,41 \pm 6,39 \pm 6$, and $30 \pm 5 \mathrm{~mm} \mathrm{Hg}$, respectively (fig. 1). The intrasubject variability was $3 \mathrm{~mm} \mathrm{Hg}$ in the retinal veins, arteries, capillaries, and in the choroid. The retinal arteriovenous $\mathrm{PO}_{2}$ difference was $10+3 \mathrm{~mm} \mathrm{Hg}$ in group 1, $13+6 \mathrm{~mm} \mathrm{Hg}$ in group 2, and $11 \pm 4 \mathrm{~mm} \mathrm{Hg}$ in combined groups 1 and 2 . The retinal arteriovenous $\mathrm{PO}_{2}$ difference was determined in each rat and shown in figure 2 . The distribution appeared relatively constant, suggesting a consistent oxygen tension drop across the vascular bed. The measured chorioretinal $\mathrm{PO}_{2}$ using

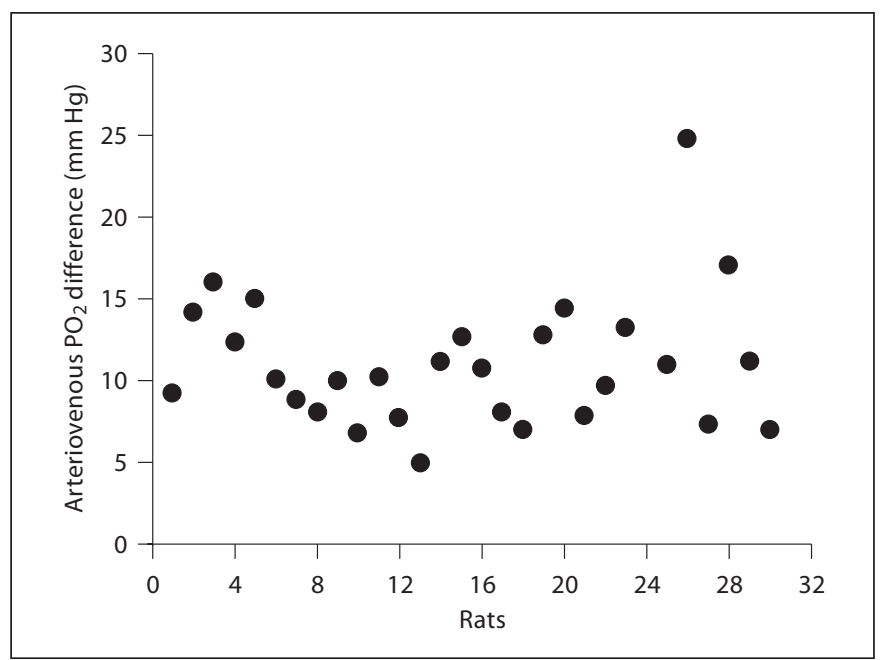

Fig. 2. The distribution of retinal arteriovenous $\mathrm{PO}_{2}$ difference in spontaneously breathing anesthetized rats $(n=29)$.

Table 2. Average $\mathrm{PO}_{2}$ (mean $\pm \mathrm{SD}$ ) measurements in the chorioretinal vasculatures in spontaneously breathing anesthetized instrumented rats

\begin{tabular}{lllll}
\hline Group & \multicolumn{4}{l}{$\mathrm{PO}_{2}, \mathrm{~mm} \mathrm{Hg}$} \\
\cline { 2 - 5 } & choroid & artery & capillaries & vein \\
\hline 1 & $50 \pm 11$ & $40 \pm 5$ & $39 \pm 6$ & $30 \pm 5$ \\
2 & $52 \pm 7$ & $43 \pm 6$ & $38 \pm 6$ & $30 \pm 5$ \\
Combined 1 \&2 & $51 \pm 10$ & $41 \pm 6$ & $39 \pm 6$ & $30 \pm 5$ \\
\hline
\end{tabular}

Group $1=$ No surgical procedure $(\mathrm{n}=22)$; group 2 = surgically instrumented $(\mathrm{n}=7)$.
Pd-porphyrin and Oxyphor R2 oxygen probes were statistically compared, indicating no significant difference $(\mathrm{p}>0.1)$.

\section{Discussion}

In the current study, systemic arterial $\mathrm{PO}_{2}$ and intravascular chorioretinal $\mathrm{PO}_{2}$ was measured in spontaneously breathing anesthetized rats. The systemic arterial $\mathrm{PO}_{2}$ of the rats in the current study was lower than that reported in previous studies $[29,30]$, which may be at- 
tributed to the respiratory-depressant effect of ketamine and xylazine anesthesia. Anesthesia with ketamine and xylazine administered over a 4-hour period has been shown to have a progressive deleterious effect on systemic oxygenation [31]. In a previous study, retinal venous $\mathrm{PO}_{2}$ in mice with only one dose of anesthesia was measured by phosphorescence imaging to be between 30 and $45 \mathrm{~mm} \mathrm{Hg}$ [23]. The measured retinal venous $\mathrm{PO}_{2}$ in our study was $30 \mathrm{~mm} \mathrm{Hg}$ and relatively constant, which may be attributed to the higher dosage and continuous administration of anesthesia. The degree of systemic hypoxia due to anesthesia was relatively constant among the rats in the current study, indicating similar cardiorespiratory conditions. Therefore, reliable baseline $\mathrm{PO}_{2}$ measurements in spontaneously breathing anesthetized rats were established.

Previous studies have demonstrated significant changes in systemic hemodynamics [32] and systemic oxygenation [33] during and immediately following major surgery, which may potentially alter ocular oxygenation. Since blood is drawn from the femoral artery to monitor systemic arterial $\mathrm{PO}_{2}$ and establish the physiologic condition of animals during experiments, it is beneficial to determine the effect of this surgical procedure on retinal oxygenation. In the current study, no significant difference was observed in the $\mathrm{PO}_{2}$ in the chorioretinal vasculatures between rats that had been subjected to surgery and those that had not. The surgical procedure of femoral artery catheterization and the associated increased time under anesthesia did not significantly affect the chorioretinal $\mathrm{PO}_{2}$.

Retinal arterial $\mathrm{PO}_{2}$ measurements were similar to previously reported measurements using a fluorescence quenching technique that measured juxta-arteriolar $\mathrm{PO}_{2}$ in spontaneously breathing anesthetized rats [34]. However, the retinal arterial and venous $\mathrm{PO}_{2}$ measurements in the current study were different compared to previously published values obtained in rats with similar systemic arterial $\mathrm{PO}_{2}$, but using a phosphorescence imaging system that lacked depth discrimination [21]. The difference in the $\mathrm{PO}_{2}$ measurements is likely related to the capability for differentiating the contribution of the signals from the choroidal and retinal vasculatures. Without depth discrimination, the retinal vascular $\mathrm{PO}_{2}$ measurements can be significantly influenced by the underlying choroid and choriocapillaris that have higher $\mathrm{PO}_{2}$ values.

As anticipated, the choroidal $\mathrm{PO}_{2}$ was comparable to the systemic arterial $\mathrm{PO}_{2}$, since the choroid is a high-flow vascular system. However, the choroidal $\mathrm{PO}_{2}$ values measured in the current study were $20 \%$ higher than mea- surements obtained in a previous study using oxygensensitive microelectrodes in hypoxic cats with comparable systemic arterial $\mathrm{PO}_{2}$ [35]. The difference between the measurements may be due to the fact that microelectrodes can penetrate both choroidal tissue and vasculature, while the molecular probe used for obtaining the majority of the data in the current study was bound to albumin and remained in the choroidal vasculature. Additionally, the use of different animal species may have also contributed to the lack of correspondence between the findings of the two studies. Though, to our knowledge, retinal capillary $\mathrm{PO}_{2}$ has not been previously measured, the $\mathrm{PO}_{2}$ is expected to be intermediate between the arterial and venous $\mathrm{PO}_{2}$. However, in the current study, the $\mathrm{PO}_{2}$ measured in the retinal capillaries was not statistically different from measurements in the retinal artery $\mathrm{PO}_{2}(\mathrm{p}>0.1)$, which seems to suggest that $\mathrm{PO}_{2}$ was measured predominantly in the capillaries near the arterial end. Also, the proximity of the measurements to the optic nerve head may have contributed to the above finding. Since there is progressive oxygen loss from the arteries, the blood in the peripheral retina has a lower $\mathrm{PO}_{2}$. The measurements in the current study were performed in areas near the optic nerve head, where venous blood contained contributions from peripheral retina and had reduced $\mathrm{PO}_{2}$, hence resulting in similar retinal capillary and artery $\mathrm{PO}_{2}$ measurements. The intrasubject variability in $\mathrm{PO}_{2}$ measurements was $3 \mathrm{~mm} \mathrm{Hg}$, indicating that changes of about $6 \mathrm{~mm} \mathrm{Hg}\left(2^{*} \mathrm{SD}\right)$ in the chorioretinal $\mathrm{PO}_{2}$ can be detected over time with $95 \%$ confidence. The intersubject variability measurements imply that patho$\operatorname{logic} \mathrm{PO}_{2}$ alterations around $8,12,12$, and $14 \mathrm{~mm} \mathrm{Hg}$ can be measured with $95 \%$ confidence in retinal veins, arteries, capillaries and the choroid, respectively. In future studies, mechanical ventilation of animals will likely further reduce the variability in the measurements. Measurement of chorioretinal $\mathrm{PO}_{2}$ in experimental animal models of retinal diseases may help elucidate the role of hypoxia in the development of retinal vascular pathologies. Overall, chorioretinal $\mathrm{PO}_{2}$ measurement has potential value for assessment of changes due to various physiological alterations.

\section{Acknowledgements}

This study was supported by the National Eye Institute, Bethesda, Md., USA, EY14917 (M.S.) and EY1792 (UIC), and an unrestricted fund from Research to Prevent Blindness, New York, N.Y. (University of Illinois at Chicago). 


\section{References}

1 Anderson DR: Is ischemia the villain in glaucomatous cupping and atrophy; in Brockhurst RJ, Boruchoff SA, Hutchinson BT, Lessell S (eds): Controversy in Ophthalmology. Philadelphia, Saunders, 1977.

-2 Bursell SE, Clermont AC, Shiba T, King GL: Evaluating retinal circulation using video fluorescein angiography in control and diabetic rats. Curr Eye Res 1992;11:287-295.

$\checkmark 3$ Stefansson E: Oxygen and diabetic eye disease. Graefes Arch Clin Exp Ophthalmol 1990;228:120-123.

4 Zarbin MA: Age-related macular degeneration: review of pathogenesis. Eur J Ophthalmol 1998;8:199-206.

5 Mordes JP, Desemone J, Rossini AA: The BB rat. Diabetes Metab Rev 1987;3:725-750.

-6 Sima AA, Chakrabarti S, Garcia-Salinas R, Basu PK: The BB-rat - an authentic model of human diabetic retinopathy. Curr Eye Res 1985;4:1087-1092.

7 Miyamoto K, Ogura Y, Nishiwaki H, et al: Evaluation of retinal microcirculatory alterations in the Goto-Kakizaki rat. A spontaneous model of non-insulin-dependent diabetes. Invest Ophthalmol Vis Sci 1996;37: 898-905.

$\checkmark 8$ Portha B, Blondel O, Serradas P, et al: The rat models of non-insulin dependent diabetes induced by neonatal streptozotocin. Diabete Metab 1989;15:61-75.

-9 Morrison J, Farrell S, Johnson E, et al: Structure and composition of the rodent lamina cribrosa. Exp Eye Res 1995;60:127-135.

-10 Satoh T, Yamaguchi K: Ocular fundus abnormalities detected by fluorescein and indocyanine green angiography in the Royal College of Surgeons dystrophic rat. Exp Anim 2000;49:275-280.

11 Matuk Y: Retinitis pigmentosa and retinal degeneration in animals: a review. Can J Biochem Cell Biol 1984;62:535-546.

-12 Linsenmeier RA, Braun RD, McRipley MA, et al: Retinal hypoxia in long-term diabetic cats. Invest Ophthalmol Vis Sci 1998;39: 1647-1657.

$\checkmark 13$ Alder VA, Su EN, Yu DY, et al: Diabetic retinopathy: early functional changes. Clin Exp Pharmacol Physiol 1997;24:785-788.
14 Cringle S, Yu DY, Alder V, Su EN: Oxygen tension and blood flow in the retina of normal and diabetic rats. Adv Exp Med Biol 1992;317:787-791.

15 Linsenmeier RA: Effects of light and darkness on oxygen distribution and consumption in the cat retina. J Gen Physiol 1986;88: 521-542.

16 Cringle SJ, Yu DY, Yu PK, Su EN: Intraretinal oxygen consumption in the rat in vivo. Invest Ophthalmol Vis Sci 2002;43:19221927.

17 Yu DY, Cringle SJ, Su EN: Intraretinal oxygen distribution in the monkey retina and the response to systemic hyperoxia. Invest Ophthalmol Vis Sci 2005;46:4728-4733.

18 Yu DY, Cringle SJ: Retinal degeneration and local oxygen metabolism. Exp Eye Res 2005; 80:745-751.

19 Berkowitz BA, Kowluru RA, Frank RN, et al: Subnormal retinal oxygenation response precedes diabetic-like retinopathy. Invest Ophthalmol Vis Sci 1999;40:2100-2105.

20 Berkowitz BA, Roberts R, Luan H, et al: Drug intervention can correct subnormal retinal oxygenation response in experimental diabetic retinopathy. Invest Ophthalmol Vis Sci 2005;46:2954-2960

21 Shonat RD, Kight AC: Oxygen tension imaging in the mouse retina. Ann Biomed Eng 2003;31:1084-1096.

22 Blumenroder S, Augustin AJ, Koch FH: The influence of intraocular pressure and systemic oxygen tension on the intravascular $\mathrm{pO}_{2}$ of the pig retina as measured with phosphorescence imaging. Surv Ophthalmol 1997;42(suppl 1):S118-S126.

23 Wilson DF, Vinogradov SA, Grosul P, et al: Oxygen distribution and vascular injury in the mouse eye measured by phosphorescence-lifetime imaging. Appl Opt 2005;44: 5239-5248.

24 Wilson DF, Vinogradov SA, Grosul P, et al: Imaging oxygen pressure in the retina of the mouse eye. Adv Exp Med Biol 2005;566:159_ 165.
25 Shahidi M, Blair NP, Mori M, Zelkha R: Feasibility of noninvasive imaging of chorioretinal oxygenation. Ophthalmic Surg Lasers Imaging 2004;35:415-422.

26 Shakoor A, Shahidi M, Blair NP, Mori M: Noninvasive assessment of chorioretinal oxygenation changes in experimental carotid occlusion. Curr Eye Res 2005;30:763-771.

27 Shahidi M, Shakoor A, Shonat R, et al: A method for measurement of chorioretinal oxygen tension. Curr Eye Res 2006;31:357366

28 ANSI: American National Standard for Safe Use of Lasers - ANSI Z136.1-1993. Orlando, Laser Institute of America, 1993.

29 Sumitra M, Manikandan P, Rao KV, et al: Cardiorespiratory effects of diazepam-ketamine, xylazine-ketamine and thiopentone anesthesia in male Wistar rats - a comparative analysis. Life Sci 2004;75:1887-1896.

30 Torbati D, Totapally BR, Camacho MT, Wolfsdorf J: Experimental critical care in ventilated rats: effect of hypercapnia on arterial oxygen-carrying capacity. J Crit Care 1999; 14:191-197.

31 Wyatt JD, Scott RA, Richardson ME: The effects of prolonged ketamine-xylazine intravenous infusion on arterial blood $\mathrm{pH}$, blood gases, mean arterial blood pressure, heart and respiratory rates, rectal temperature and reflexes in the rabbit. Lab Anim Sci 1989;39: 411-416.

32 Oztas B, Akgul S, Arslan FB: Influence of surgical pain stress on the blood-brain barrier permeability in rats. Life Sci 2004;74: 1973-1979.

33 Phillips AS, Mirakhur RK, Glen JB, Hunter SC: Total intravenous anaesthesia with propofol or inhalational anaesthesia with isoflurane for major abdominal surgery. Recovery characteristics and postoperative oxygenation - an international multicentre study. Anaesthesia 1996;51:1055-1059.

34 Zuckerman R, Cheasty JE, Wang Y: Optical mapping of inner retinal tissue $\mathrm{PO}_{2}$. Curr Eye Res 1993;12:809-825.

-35 Linsenmeier RA, Braun RD: Oxygen distribution and consumption in the cat retina during normoxia and hypoxemia. J Gen Physiol 1992;99:177-197. 